NASA/TM—2012-217661

\title{
Dynamic Load Measurement of Ballistic Gelatin Impact Using an Instrumented Tube
}

J.D. Seidt

The Ohio State University, Columbus, Ohio

J.M. Pereira

Glenn Research Center, Cleveland, Ohio

J.T. Hammer and A. Gilat

The Ohio State University, Columbus, Ohio

C.R. Ruggeri

Glenn Research Center, Cleveland, Ohio 


\section{NASA STI Program . . . in Profile}

Since its founding, NASA has been dedicated to the advancement of aeronautics and space science. The NASA Scientific and Technical Information (STI) program plays a key part in helping NASA maintain this important role.

The NASA STI Program operates under the auspices of the Agency Chief Information Officer. It collects, organizes, provides for archiving, and disseminates NASA's STI. The NASA STI program provides access to the NASA Aeronautics and Space Database and its public interface, the NASA Technical Reports Server, thus providing one of the largest collections of aeronautical and space science STI in the world. Results are published in both non-NASA channels and by NASA in the NASA STI Report Series, which includes the following report types:

- TECHNICAL PUBLICATION. Reports of completed research or a major significant phase of research that present the results of NASA programs and include extensive data or theoretical analysis. Includes compilations of significant scientific and technical data and information deemed to be of continuing reference value. NASA counterpart of peer-reviewed formal professional papers but has less stringent limitations on manuscript length and extent of graphic presentations.

- TECHNICAL MEMORANDUM. Scientific and technical findings that are preliminary or of specialized interest, e.g., quick release reports, working papers, and bibliographies that contain minimal annotation. Does not contain extensive analysis.

- CONTRACTOR REPORT. Scientific and technical findings by NASA-sponsored contractors and grantees.
- CONFERENCE PUBLICATION. Collected papers from scientific and technical conferences, symposia, seminars, or other meetings sponsored or cosponsored by NASA.

- SPECIAL PUBLICATION. Scientific, technical, or historical information from NASA programs, projects, and missions, often concerned with subjects having substantial public interest.

- TECHNICAL TRANSLATION. Englishlanguage translations of foreign scientific and technical material pertinent to NASA's mission.

Specialized services also include creating custom thesauri, building customized databases, organizing and publishing research results.

For more information about the NASA STI program, see the following:

- Access the NASA STI program home page at http://www.sti.nasa.gov

- E-mail your question to help@sti.nasa.gov

- Fax your question to the NASA STI Information Desk at 443-757-5803

- Phone the NASA STI Information Desk at 443-757-5802

- Write to: STI Information Desk NASA Center for AeroSpace Information 7115 Standard Drive Hanover, MD 21076-1320 
NASA/TM—2012-217661

\section{Dynamic Load Measurement of Ballistic Gelatin Impact Using an Instrumented Tube}

\section{J.D. Seidt}

The Ohio State University, Columbus, Ohio

J.M. Pereira

Glenn Research Center, Cleveland, Ohio

J.T. Hammer and A. Gilat

The Ohio State University, Columbus, Ohio

C.R. Ruggeri

Glenn Research Center, Cleveland, Ohio

Prepared for the

XII International Congress and Exposition on Experimental and Applied Mechanics sponsored by the Society for Experimental Mechanics Costa Mesa, California, June 11-14, 2012

National Aeronautics and

Space Administration

Glenn Research Center

Cleveland, Ohio 44135 


\section{Acknowledgments}

Support was received by the National Aeronautics and Space Administration Aviation Safety Project. The authors would like to acknowledge the useful advice and assistance of Duane Revilock, and Jeff Hammel of the NASA Glenn Research Center Ballistic Impact Facility. This work was supported in part by an allocation of computing time from the Ohio Supercomputer Center (OSC). This work was sponsored by the Aviation Safety at the NASA Glenn Research Center.

Trade names and trademarks are used in this report for identification only. Their usage does not constitute an official endorsement, either expressed or implied, by the National Aeronautics and Space Administration.

Level of Review: This material has been technically reviewed by technical management.

Available from

NASA Center for Aerospace Information 7115 Standard Drive

Hanover, MD 21076-1320
National Technical Information Service 5301 Shawnee Road Alexandria, VA 22312 


\title{
Dynamic Load Measurement of Ballistic Gelatin Impact Using an Instrumented Tube
}

\author{
J.D. Seidt \\ The Ohio State University \\ Columbus, Ohio 43210 \\ J.M. Pereira \\ National Aeronautics and Space Administration \\ Glenn Research Center \\ Cleveland, Ohio 44135 \\ J.T. Hammer and A. Gilat \\ The Ohio State University \\ Columbus, Ohio 43210 \\ C.R. Ruggeri \\ National Aeronautics and Space Administration \\ Glenn Research Center \\ Cleveland, Ohio 44135
}

\begin{abstract}
Bird strikes are a common problem for the aerospace industry and can cause serious damage to an aircraft. Ballistic gelatin is frequently used as a surrogate for actual bird carcasses in bird strike tests. Numerical simulations of these tests are used to supplement experimental data, therefore it is necessary to use numerical modeling techniques that can accurately capture the dynamic response of ballistic gelatin. An experimental technique is introduced to validate these modeling techniques. A ballistic gelatin projectile is fired into a strike plate attached to a 36 in. long sensor tube. Dynamic load is measured at two locations relative to the strike plate using strain gages configured in a full Wheatstone bridge. Data from these experiments are used to validate a gelatin constitutive model. Simulations of the apparatus are analyzed to investigate its performance.
\end{abstract}

\section{Introduction}

Bird strikes can inflict serious damage to an aircraft. Photographs of bird strike damage to a Boeing 767-300 aircraft are presented in Figure 1 (Ref. 1). This aircraft was damaged by large birds as it climbed from Charles de Gaulle Airport in Paris. The cockpit area of the aircraft was perforated by the birds, causing depressurization. Fortunately, the crew safely returned to the airport and no injuries were reported. Another recent and well-publicized example of bird strike damage is the January $15^{\text {th }} 2009$ incident involving US Airways Flight 1549. The captain of the Airbus A320-214 was forced to make an emergency landing on the Hudson River after both engines ingested Canada geese resulting in a complete loss of thrust (Ref. 2). Because of many incidents like these, aircraft structures and engines must be certified to operate safely after a bird strike or ingestion event.

Certification tests are conducted using actual bird carcasses (Ref. 3); however, ballistic gelatin is frequently used as a surrogate material for preliminary testing. The main advantage to using gelatin for testing is repeatability. No two birds are identical, even if they are of the same species. These natural variations make it difficult to perform repeatable experiments (Ref. 4). In addition, there are obvious sanitary benefits to testing with gelatin opposed to actual birds. Wilbeck and Rand (Ref. 4) developed a bird substitute by mixing commercial gelatin with phenolic microballoons. The authors note that this surrogate projectile creates impact loads similar to those generated by actual birds. 

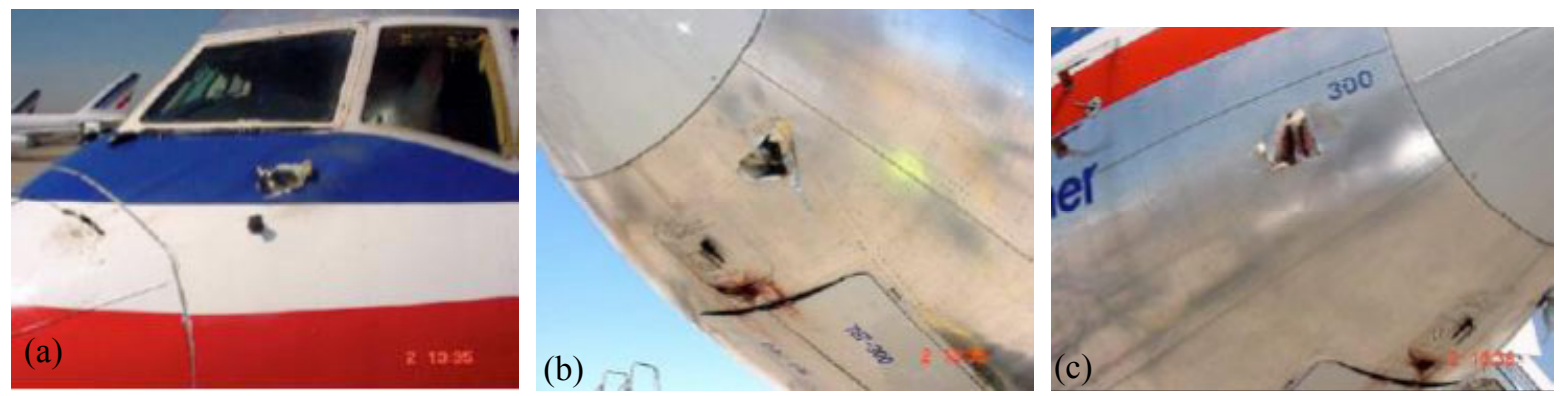

Figure 1.-Photographs of bird strike damage to a Boeing 767-300 aircraft (Ref. 1): (a) below cockpit window, (b) underside fuselage, (c) aft of radome.

Many researchers have conducted numerical simulations of bird impact with various aircraft structures, such as wing leading edges (Ref. 5), windshields (Ref. 6), flaps (Ref. 7), and engine blades (Ref. 8). The majority of these simulations treat the bird as circular cylinders with rounded edges, and assume that the birds will behave hydrodynamically on impact. In these studies, various numerical treatments of the bird model are used, including Lagrangian, Arbitrary Lagrangian Eulerian (ALE), and Smoothed Particle Hydrodynamics (SPH). These simulations need to be validated by comparing the results to experimental data.

An experimental measurement of the dynamic force imparted into a target by a projectile is very useful to validate simulations. However, impact force measurements are difficult to obtain accurately because of the short duration of the load. Even piezoelectric load cells with the highest frequency response are generally not sufficient to measure forces involved in ballistic impact events, and resonances in the supporting structure typically make results difficult to interpret and simulate. In the past, gelatin impact experiments have been conducted by firing a projectile into a flat plate instrumented with different types of pressure transducers (Refs. 9 and 10). Typically, the diameter of the pressure transducer is less than the diameter of the gelatin projectile. The pressure on the impacting face of the projectile is certainly non-uniform, especially when the projectile begins to "mushroom". The pressure is maximum at the center and decreases radially outward. If it is assumed that the pressure measured by the transducer is applied to the entire impacting surface area, the impulse transmitted to the target by the projectile could be substantially overestimated. While pressure measurements can be very valuable, it is also useful to measure the overall impact force. In this paper, a tubular sensor is used to measure the transmitted force from an impacting gelatin projectile. These results are compared to simulations of the measurement device to determine how the measured response varies from the input loading function.

\section{Experimental}

The tube sensor (Fig. 2) is a 36 in. long 2024-T3 aluminum drawn tube with an outside diameter of 3.5 in. and a 0.125 in. thick wall. The tube dimensions were chosen such that the waves transmitted along the tube would remain elastic during the impact loading. Transmitted forces were anticipated to be roughly $20,000 \mathrm{lb}$, thus the peak dynamic stress in the tube is $15.1 \mathrm{ksi}, 30$ percent of the yield strength for 2024-T3 aluminum (50.0 ksi). A 0.5 in. thick 7075-T6 aluminum strike plate is attached to end of the tube to serve as a contact surface for the gelatin projectile.

The tube is instrumented with Vishay Micro-Measurements EA-06-125BZ-350 electric resistance strain gages configured in full Wheatstone bridges at two locations: 6 and $12 \mathrm{in}$. from the front edge of the tube. For each bridge, two strain gages are oriented in the axial (loading) direction and two are oriented in the transverse direction, a configuration commonly used for load cells. The sensitivity of each bridge is:

$$
\frac{\Delta E}{V}=\frac{S_{g} F}{2 A E}(1+v)
$$



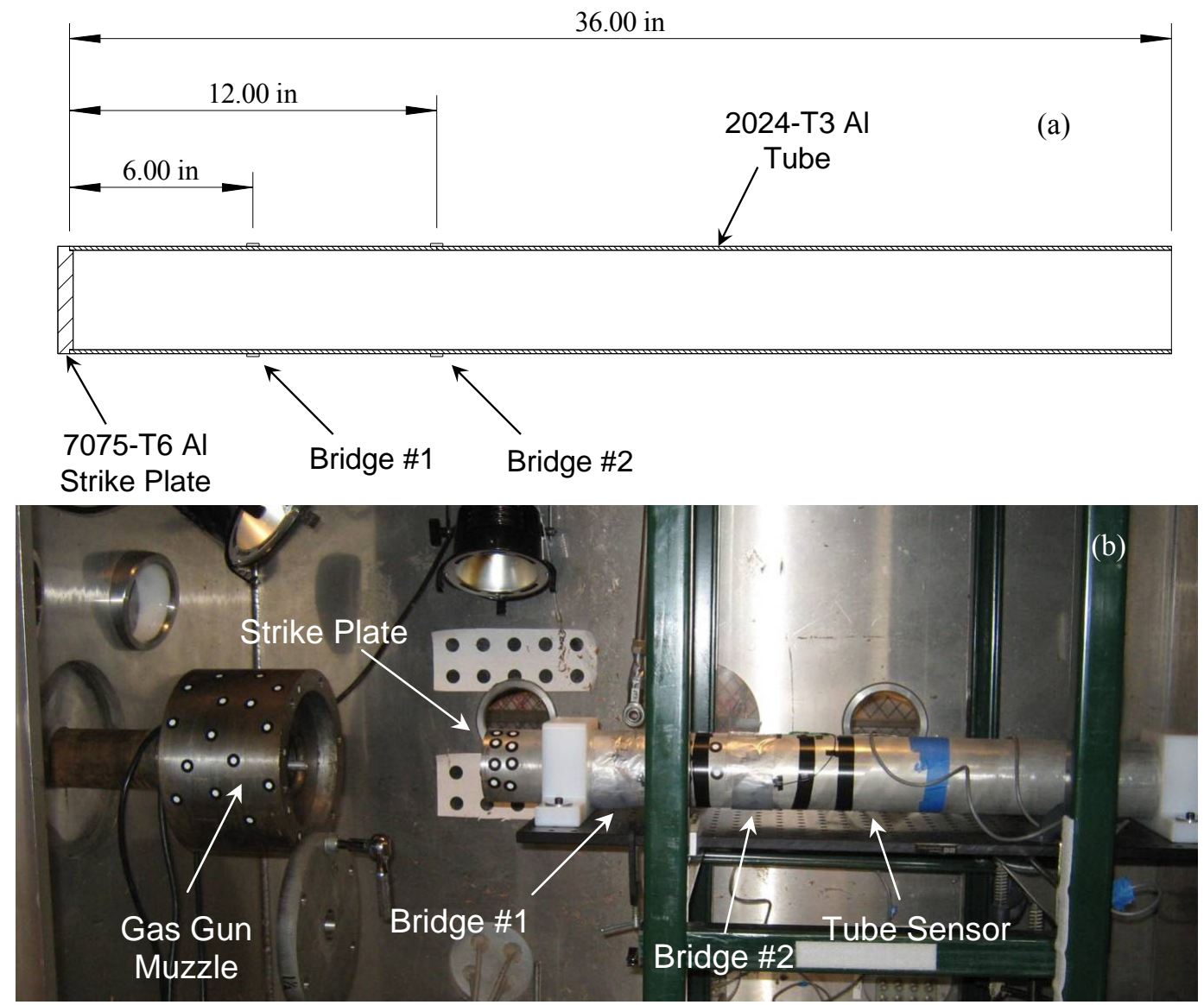

Figure 2.-Tube sensor: (a) section schematic of the tube, (b) photo of the sensor and experimental setup.

where, $\Delta E$ is the signal voltage, $V$ is the excitation voltage, $S_{g}$ is the gage factor, $F$ is the force in the tube, $A$ is the tube's cross-sectional area and $E$ and $v$ are the Young's modulus and Poisson's ratio of the tube, respectively. The strain gages have a gage factor of 2.105 , so for $10 \mathrm{~V}$ excitation, the sensitivity is $0.996 \mathrm{mV}$ per kip. For comparison, a solid $3.5 \mathrm{in}$. diameter rod with the same instrumentation would have a sensitivity of $0.137 \mathrm{mV}$ per kip.

Bridge \#1 can measure an impact event that is $297 \mu$ s long. This is the duration required for an elastic wave, traveling at 201,884 in./s, to traverse $60 \mathrm{in}$. or twice the distance from the bridge to the end of the tube. After $297 \mu \mathrm{s}$, the measurement from the bridge is affected by the beginning of the reflected wave. Bridge \#2 can only measure a $238 \mu$ s event, since this bridge is 6 in. closer to the end of the tube.

The projectiles (Fig. 3) were nominally 1.25 in. diameter, 3.0 in. long cylinders, made up of gelatin, water and phenolic microballoons used to modify the density. A 20 percent gelatin mixture recipe was used with the appropriate volume of phenolic micro-spheres needed to attain the desired specific gravity of the projectile. The ratio of gelatin to water is defined on a mass basis; the percent gelatin is defined by the ratio of gelatin mass to the total mass of gelatin and water. The desired specific gravity of the projectiles was 0.95 . A detailed projectile manufacturing procedure was followed to ensure reproducible projectile characteristics.

The gelatin projectiles were accelerated by a single stage light gas gun using helium as the driving gas. The gun has a bore diameter of $2 \mathrm{in}$. and a $12 \mathrm{ft}$ long barrel. Instrumentation systems were placed inside a vacuum chamber mated to the gun barrel. The projectiles were carried down the barrel in polycarbonate sabots (Fig. 3) that were arrested by a sabot stopper at the muzzle. When arrested, the sabot remains in contact with the stopper providing a seal which prevents the high pressure propellant gas in the barrel from affecting the vacuum chamber pressure. 


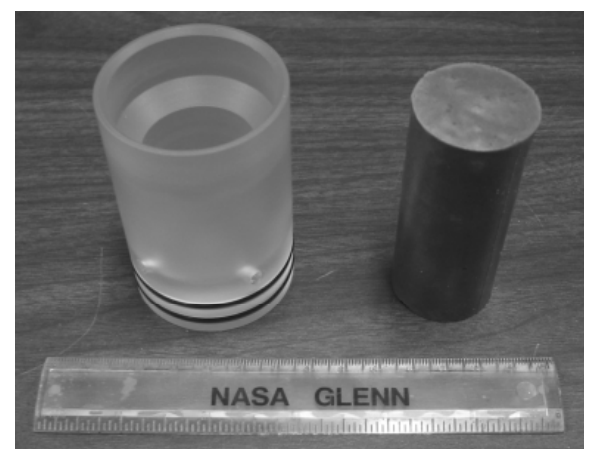

Figure 3.-Polycarbonate sabot and gelatin projectile.

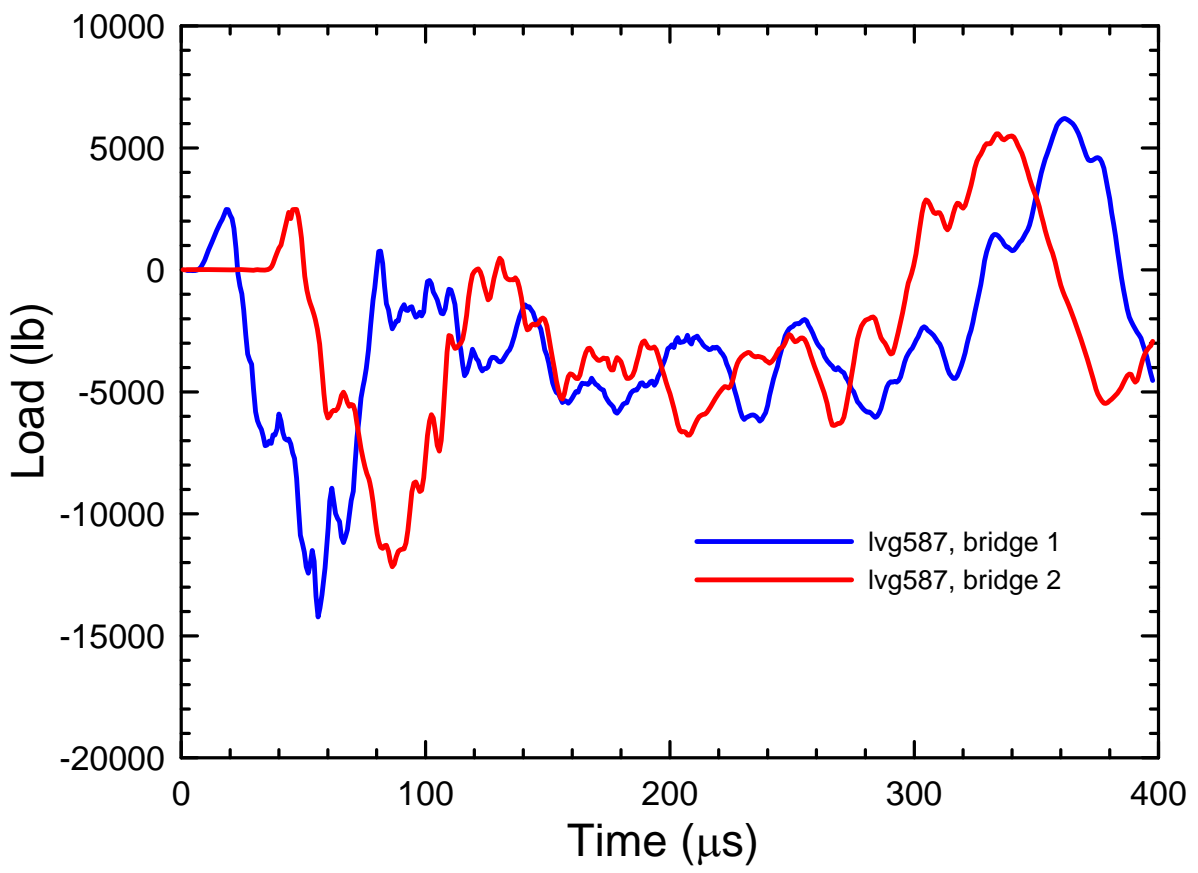

Figure 4.-Tube sensor data from a gelatin impact test, projectile velocity: $504 \mathrm{ft} / \mathrm{s}$.

Tube sensor data was recorded using a Spectral Dynamics 2805 data acquisition module at a rate of $1.25 \mathrm{E} 6 \mathrm{samples} / \mathrm{sec}$. The projectile orientation and speed were computed using a calibrated pair of Vision Research Phantom V7.3 cameras and GOM's PONTOS digital image correlation point tracking software. The cameras recorded images at a rate of 10,000 frames/sec and a resolution of 704 (horizontal) x 424 (vertical) pixels. The software tracked the three-dimensional positions of points marked on the projectile as a function of time. A third Phantom V7.3 camera served as a backup system for measuring projectile speed. This camera was oriented normal to the projectile path and acquired images at 20,000 frames/sec.

Figures 4 and 5 present results from an experiment in which the projectile impacted the strike plate at $504 \mathrm{ft} / \mathrm{s}$. The output history of the tube sensor is shown in Figure 4. The blue trace is the output from bridge \#1 and the red trace is the output from bridge \#2. Both bridges show an initial tensile load of roughly $2500 \mathrm{lb}$ followed by a compressive peak of $-13,000 \mathrm{lb}$ and then a $240 \mu$ s long region where the load oscillates about $-4000 \mathrm{lb}$. The initial tensile pulse is discussed in the next section. The compressive peak measured by bridge \#1 $(-14,500 \mathrm{lb})$ has a larger magnitude than that measured by bridge \#2 $(-12,500 \mathrm{lb})$. There are also other minor differences between the measurements from bridge \#1 and \#2. This is evidence of dispersion. The three regimes of Wilbeck's model for soft projectiles (Ref. 11) can be seen in the data. The initial compressive peak corresponds to the shock development regime. The release wave regime coincides with the drop in compressive force. The steady flow regime coincides with the 

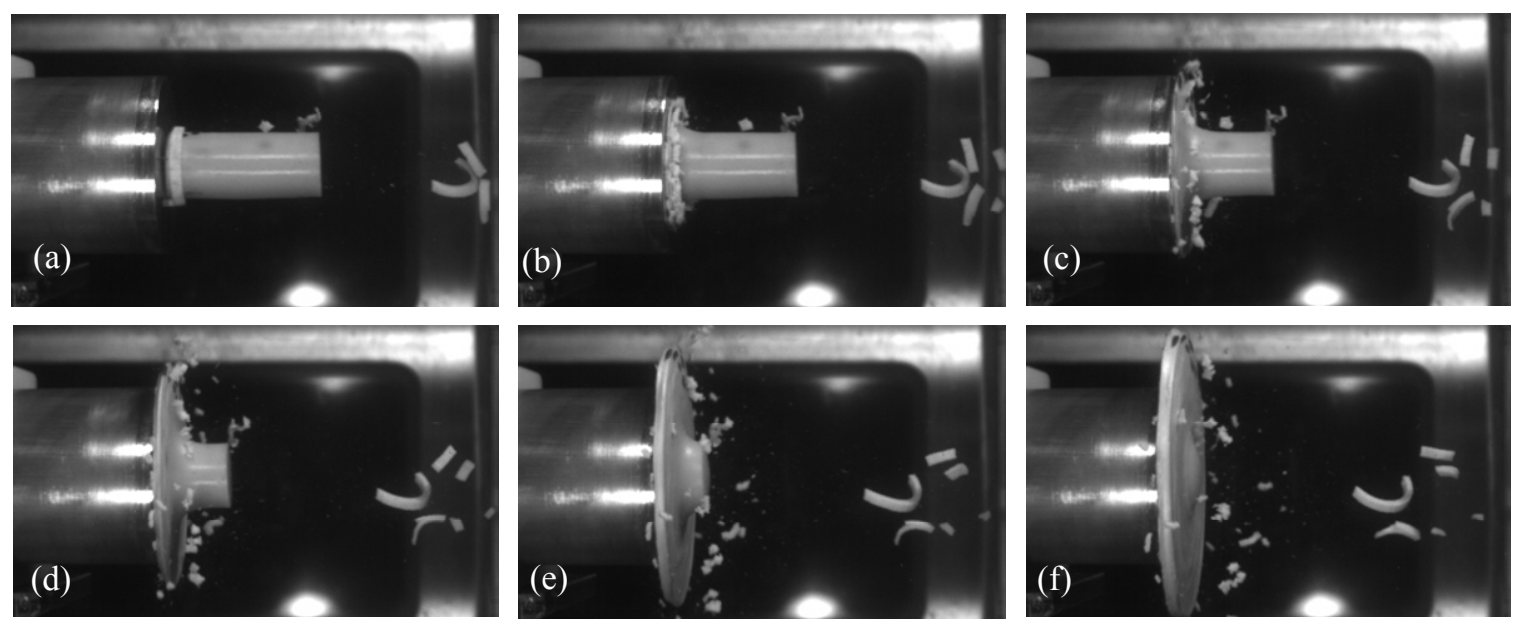

Figure 5.-Sequence of a gelatin projectile impacting the strike plate of the tube sensor at $504 \mathrm{ft} / \mathrm{s}$.

region of relatively constant force. Figure 5 shows a series of sequential images from the high speed camera oriented normal to the projectile path. Figure 5(a) shows the projectile just prior to impact. Figure 5(b) shows the projectile just after impact. The impact sequence develops in Figure 5(c), (d), (e), and (f). $100 \mu$ s elapse between each image, so the sequence represents a $500 \mu$ s duration. The white debris visible in the images is light foam that was used to support the projectile in the sabot.

\section{Numerical Simulations}

LS-DYNA (Ref. 12) simulations were used to evaluate the performance of the tube sensor. Threedimensional, eight-noded, constant stress solid elements were used to mesh the strike plate and the tube. The mesh was constructed of elements with approximate aspect ratios of 1.0 and lengths of 1/32 in. The strike plate had 112 elements across its diameter and 16 elements through the thickness. The tube had four elements through the thickness and 1152 elements along its length. The simulation contained roughly 1.6 million total elements. Both the strike plate and the tube were modeled as elastic materials with $E, v$, and $\rho$ as $73.1 \mathrm{GPa}, 0.33$, and $2.78 \mathrm{gm} / \mathrm{cc}$, respectively. An assumed, evenly distributed pressure history was applied to the center of the strike plate. It was applied over a 1.25 in diameter circle, the same diameter of the gelatin projectile. This pressure multiplied by the area gives a dynamic load history to compare to the tube sensor output.

Simulated dynamic forces are compared to experimental results in Figure 6. The solid black trace is the input load history applied to the center of the strike plate. The input load has a rise time of $5 \mu$ s and a peak compressive load of $-9000 \mathrm{lb}$. After peak load, it decays to a force of $-3800 \mathrm{lb}$ and remains there for $400 \mu \mathrm{s}$. Simulated forces, calculated from the strain histories of elements at locations that correspond with bridge $\# 1$ and \#2 on the actual sensor are represented by dashed blue and red traces, respectively. Solid blue and red traces are actual experimental data measured by the tube sensor. The simulated dynamic loads agree quite well with those measured experimentally. The loads measured by the tube, however, are substantially different than the input load history. The peak compressive load measured by the tube sensor is roughly 40 percent higher than the peak input force. The steady flow region (constant load), however, is reasonably well captured by the sensor until the reflected pulse arrives at the bridge. Another obvious discrepancy between the input and output load is the presence of the initial tensile pulse that was both measured experimentally and calculated in the simulation. The source of the tensile pulse is deformation in the strike plate. Figure 7 shows the simulated strike plate deformation at various times after load initiation. As the load increases, the strike plate bends elastically into the tube. Figure 7(a) is a plot of the axial deflection of points distributed along the diameter of the strike plate. The bending draws the material of the strike plate radially inward. Figure 7(b) shows the radial displacement of points distributed 


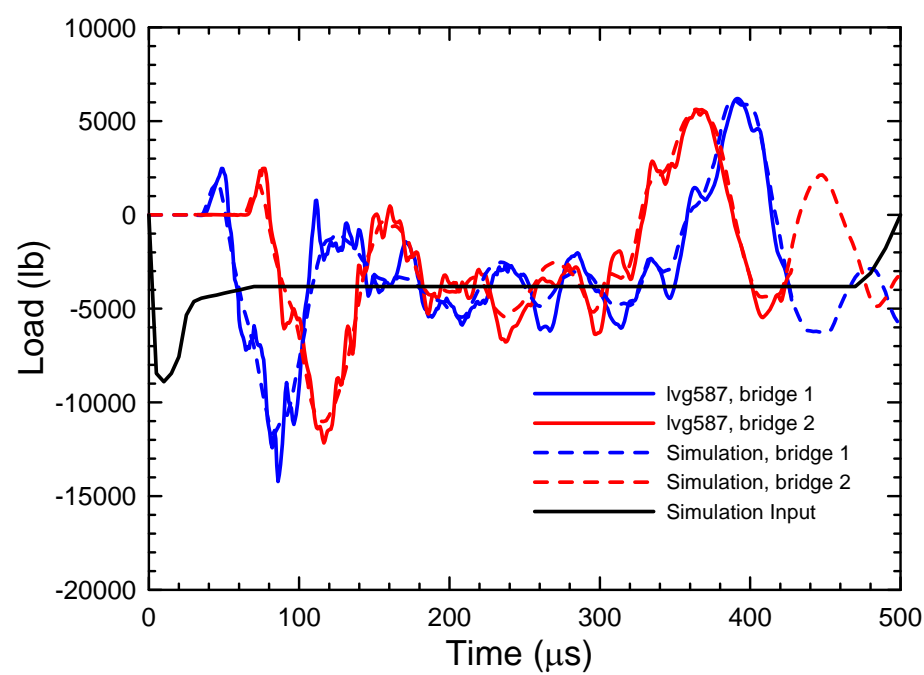

Figure 6.-Comparison of experimental and simulated dynamic forces.

(a)

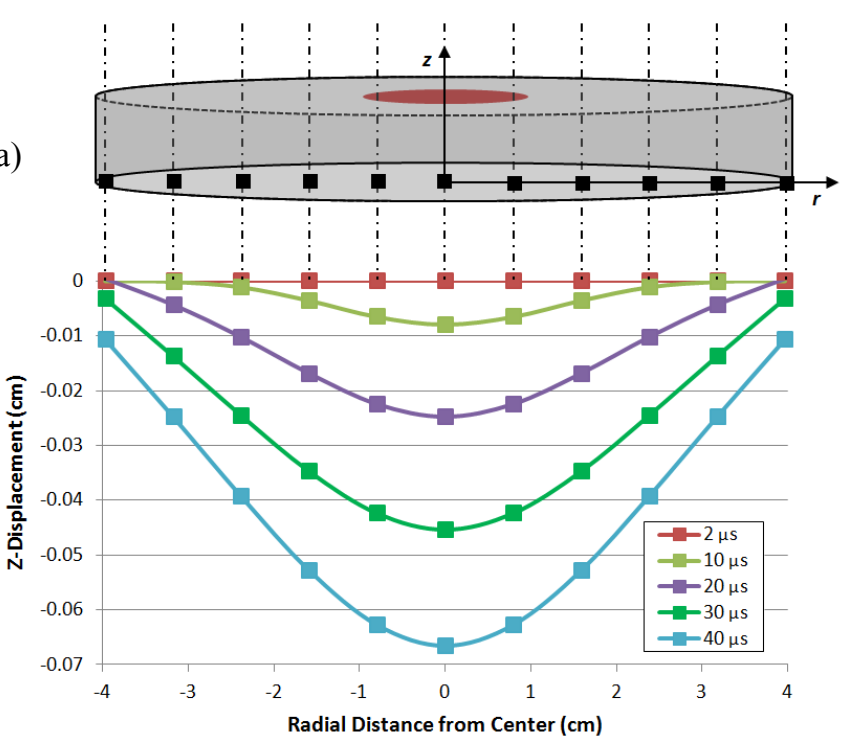

(b)

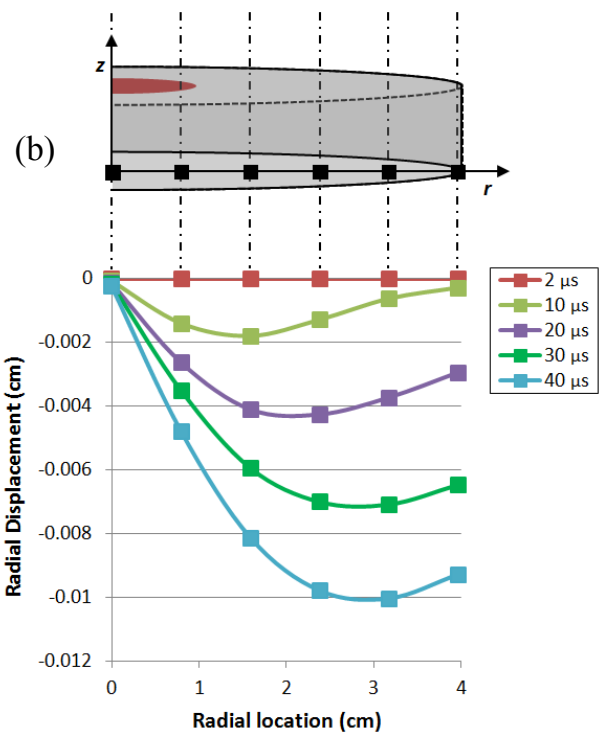

Figure 7.-Strike plate deformation at different times after load: (a) axial bending, (b) radial contraction.

along the radius of the plate. As the load accumulates negative radial displacements arise. The tube is attached to the strike plate, so it also is drawn inward. This uniform radial contraction creates the tensile pulse evident in both the experimental and simulated results at the bridge locations.

The results in Figure 6 show that the tube sensor output significantly overestimates the peak compressive input load. Additional simulations were run to determine how the pressure load input characteristics affect the measurement error. These characteristics include the rise time and shape of the load history. Results from this study are shown in Figure 8. Results are presented from four simulations where the tube sensor was subjected to different load histories. The load histories are represented by dashed traces. The input load history for simulation \#1, represented by the blue trace, is identical to the one shown in Figure 6. It has a rise time of $5 \mu \mathrm{s}$, a peak load of $-9000 \mathrm{lb}$ followed by an unloading tail to a constant load of $-3800 \mathrm{lb}$. The input history for simulation \#2 (red trace) is identical to that of simulation \#1 except it has a $25 \mu$ s rise time. Simulations \#3 (green trace) and \#4 (black trace) are subjected to a $-9000 \mathrm{lb}$ step load history with 25 and $100 \mu$ s rise times, respectively. The tube output, measured at a location corresponding to bridge \#1, is represented by solid traces. The initial tensile pulse amplitude decays with increasing rise time. In all four simulations, the tube sensor output overestimates 


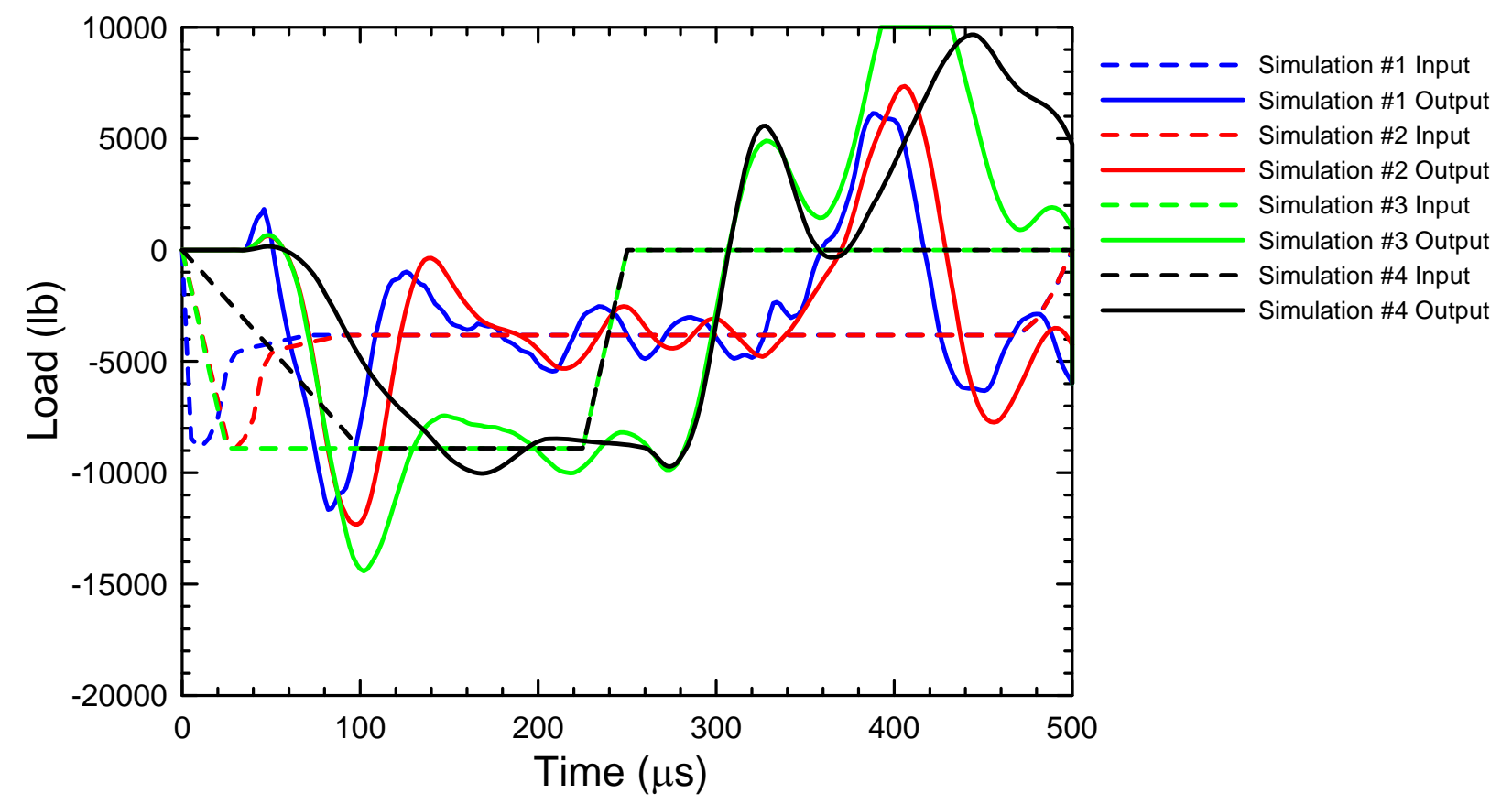

Figure 8.-Results from simulations of the sensor tube subjected to four different load histories.

the peak compressive load input. The data in Figure 8 illustrate that this overshoot is dependent on both the rise time and the shape of the load pulse. It is not solely dependent on rise time, since the overshoot from simulation \#1, which has the fastest rise time $(5 \mu \mathrm{s})$, is less than those from simulation \#2 and \#3 which both have a rise time of $25 \mu \mathrm{s}$. The overshoot from simulation \#3 is substantially higher than that from simulation $\# 2$, showing that this phenomenon is dependent on the shape of the load as well. The impulse of the input load for simulation $\# 3$ is significantly larger than that from simulation $\# 2$. Therefore, the overshoot becomes worse with increasing impulse. This also explains why simulation \#2's overshoot is larger than that of simulation \#1. The input load impulse of simulation \#2 is slightly larger than that from simulation \#1, since there is more area under the $25 \mu$ s ramp than there is under the $5 \mu \mathrm{s}$ ramp. The results of simulation \#4 show that the rise time also plays a role since the $100 \mu$ s rise time step load gives the least overshoot.

No attempt was made to optimize the geometry of the tube sensor. It is likely that the geometry can be modified to minimize errors between the input and measured loads. Although the measured output is not always identical to the input load, the tube sensor is still a useful tool to validate numerical models of ballistic gelatin. The experimental data can be compared to results of a validation simulation in which a proposed numerical treatment of a gelatin projectile is fired into a model of the tube sensor. This comparison can be used as a performance metric for the gelatin model. The simple geometry of the sensor is easily incorporated into simulations, making validation simulations relatively straightforward.

\section{Summary and Conclusions}

A tube sensor was used to measure dynamic impact forces from ballistic gelatin projectiles. The sensor consists of a 0.5 in. thick 7075-T6 aluminum strike plate attached to 36 in. long 2024-T3 aluminum tube with a $3.5 \mathrm{in}$. outside diameter and $0.125 \mathrm{in}$. thick wall. The tube was instrumented with electrical resistance strain gages at two locations: 6 and $12 \mathrm{in.} \mathrm{from} \mathrm{the} \mathrm{edge} \mathrm{of} \mathrm{the} \mathrm{tube.} 1.25 \mathrm{in}$. diameter, $3.0 \mathrm{in}$. long gelatin projectiles were fired normal to the tube's strike plate at velocities of roughly $450 \mathrm{ft} / \mathrm{s}$ using a single stage light gas gun. Data from the tube sensor's strain gages were recorded and high speed cameras were used to determine the projectile's velocity and orientation prior to impact. 
LS-DYNA simulations were used to investigate the performance of the tube sensor. Simulated output from the tube matched the experimental data well. The deformation of the tube's strike plate was identified as the source of an initial tensile pulse found in both experimental data and the simulation results. A numerical investigation of the sensor's response to various input load histories was conducted. The results show that the tube sensor overestimates the peak compressive load for all four input loads considered. The magnitude of this overshoot is dependent on both the rise time and shape of the load input. Fast rise-time, high impulse load histories lead to large overshoots. Reducing the impulse and increasing the rise time of the load history reduce the overshoot. Measurement errors can likely be reduced by optimizing the sensor's geometry.

The tube sensor is a useful tool to validate numerical models of ballistic gelatin projectiles. It can easily be incorporated into validation simulations allowing the simulated and experimental sensor response to be directly compared.

\section{References}

1. Tiffany, C.F., Gallagher, J.P., Babish, C.A., "Threats to Aircraft Structural Safety, Including a Compendium of Selected Structural Accidents/Incidents". Aeronautical Systems Center Technical Report \#ASC-TR-2010-5002, March, 2010.

2. "Loss of Thrust in Both Engines After Encountering a Flock of Birds and Subsequent Ditching on the Hudson River, US Airways Flight 1549, Airbus A320-214, N106US, Weehawken, New Jersey, January 15,2009," NTSB Accident Report \#NTSB/AAR-10/3, PB2010-910403, May $4^{\text {th }} 2010$.

3. McCallum, S.C., Constantinou, C., "The Influence of Bird-Shape in Bird-Strike Analysis," Proceedings of the $5^{\text {th }}$ European LS-DYNA Users Conference, Birmingham, UK, May, 2005.

4. Wilbeck, J.S., Rand, J.L., "The Development of a Substitute Bird Model," Journal of Engineering Power, Vol. 103, 1981, pp 725-730.

5. McCarthy, M.A., Xiao, J.R., McCarthy, C.T., Kamoulakos, A., Ramos, J., Gallard, J.P., Melito, V., "Modelling of Bird Strike on Aircraft Wing Leading Edge from Fibre Metal Laminates - Part 2: Modelling of Impact with SPH Bird Model," Applied Composite Structures, Vol. 11, 2004, pp 317340 .

6. Wang, F.S., Yue, Z.F., "Numerical Simulation of Damage and Failure in Aircraft Windshield Structure Against Bird Strike, Materials and Design, Vol. 31, 2010, pp 687-695.

7. Ivancevic, D., Smojver, I., "Hybrid Approach in Bird Strike Damage Prediction on Aeronautical Composite Structures," Composite Structures, Vol. 94, 2011. pp 15-23.

8. Mau, R.H., Meguid, S.A., Ng T.Y., "Transient Three Dimensional Finite Element Analysis of a Bird Striking a Fan Blade," International Journal of Mechanics and Materials in Design, Vol. 4, pp 79-96.

9. Lavoie, M.A., Gakwaya, A., Nejad Ensan, M., Zimcik, D.G. and Nadlall, D. "Bird's Substitute Tests Results and Evaluation of Available Numerical Methods," International Journal of Impact Engineering, Vol. 36, 2009, pp 1276-1287.

10. Barber, J.P, Taylor, H.R., and Wilbeck, J.S., "Characterization of Bird Impacts on a Rigid Plate: Part 1," Air Force Flight Dynamics Laboratory Technical Report \#AFFDL-TR-75-5, Jan. 1975.

11. Wilbeck, J., "Impact Behavior of Low Strength Projectiles," Air Force Materials Laboratory Technical Report \#AFML-TR-77-134, July, 1978.

12. “LS-DYNA Keyword User's Manual," Version 971, Livermore Software Technology Corporation (LSTC), May, 2007. 



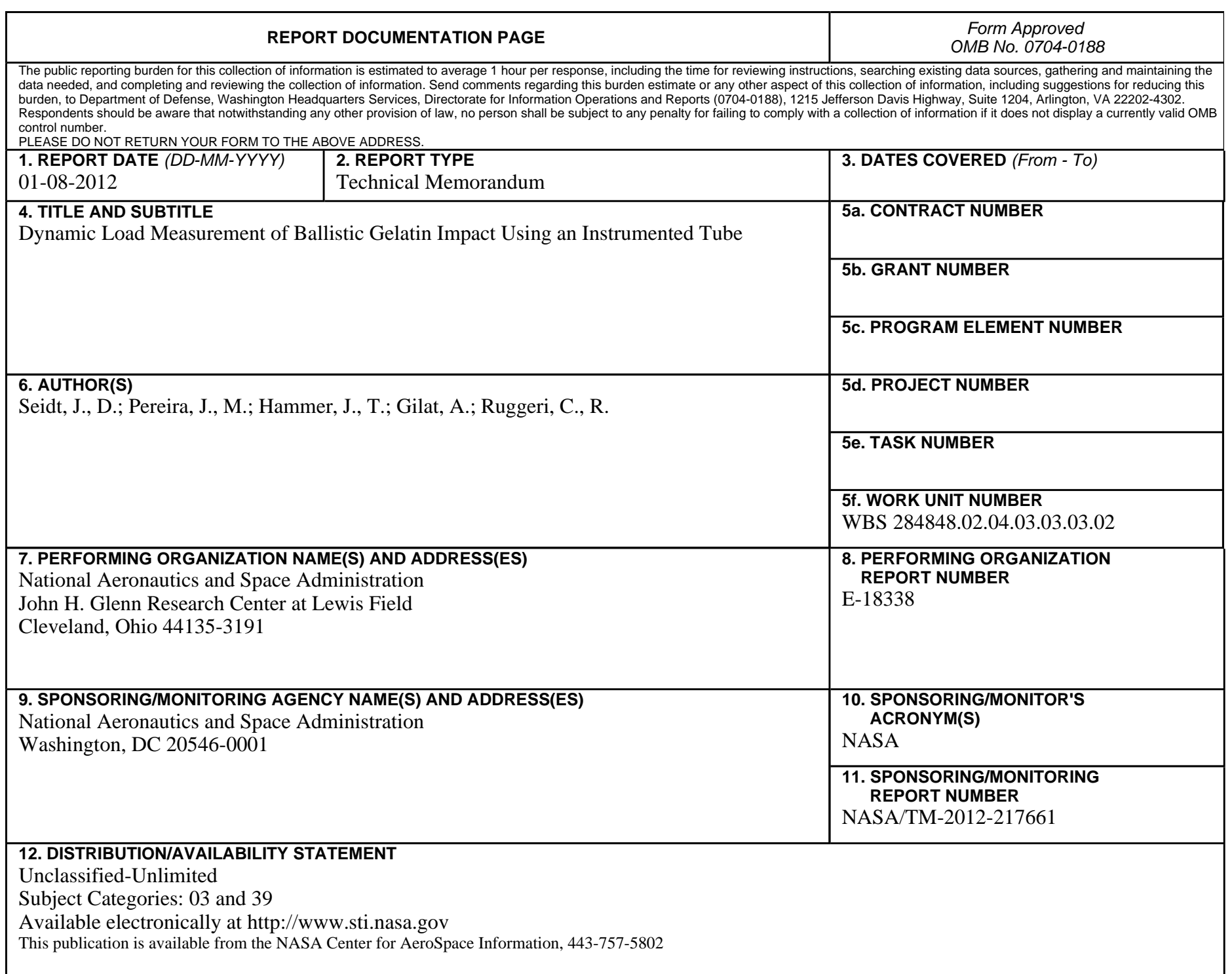

\section{SUPPLEMENTARY NOTES}

\section{ABSTRACT}

Bird strikes are a common problem for the aerospace industry and can cause serious damage to an aircraft. Ballistic gelatin is frequently used as a surrogate for actual bird carcasses in bird strike tests. Numerical simulations of these tests are used to supplement experimental data, therefore it is necessary to use numerical modeling techniques that can accurately capture the dynamic response of ballistic gelatin. An experimental technique is introduced to validate these modeling techniques. A ballistic gelatin projectile is fired into a strike plate attached to a 36 in. long sensor tube. Dynamic load is measured at two locations relative to the strike plate using strain gages configured in a full Wheatstone bridge. Data from these experiments are used to validate a gelatin constitutive model. Simulations of the apparatus are analyzed to investigate its performance.

15. SUBJECT TERMS

Bird-aircraft collisions; Terminal ballistics

\begin{tabular}{|c|c|c|c|c|c|}
\hline \multicolumn{3}{|c|}{ 16. SECURITY CLASSIFICATION OF: } & \multirow{2}{*}{$\begin{array}{l}\text { 17. LIMITATION OF } \\
\text { ABSTRACT } \\
\text { UU }\end{array}$} & \multirow{2}{*}{$\begin{array}{l}\text { 18. NUMBER } \\
\text { OF } \\
\text { PAGES } \\
16\end{array}$} & \multirow{2}{*}{$\begin{array}{l}\text { 19a. NAME OF RESPONSIBLE PERSON } \\
\text { STI Help Desk (email:help@sti.nasa.gov) } \\
\text { 19b. TELEPHONE NUMBER (include area code) } \\
\text { 443-757-5802 }\end{array}$} \\
\hline $\begin{array}{l}\text { a. REPORT } \\
\text { U }\end{array}$ & $\begin{array}{l}\text { b. ABSTRACT } \\
\text { U }\end{array}$ & $\begin{array}{l}\text { c. THIS } \\
\text { PAGE } \\
\text { U }\end{array}$ & & & \\
\hline
\end{tabular}



